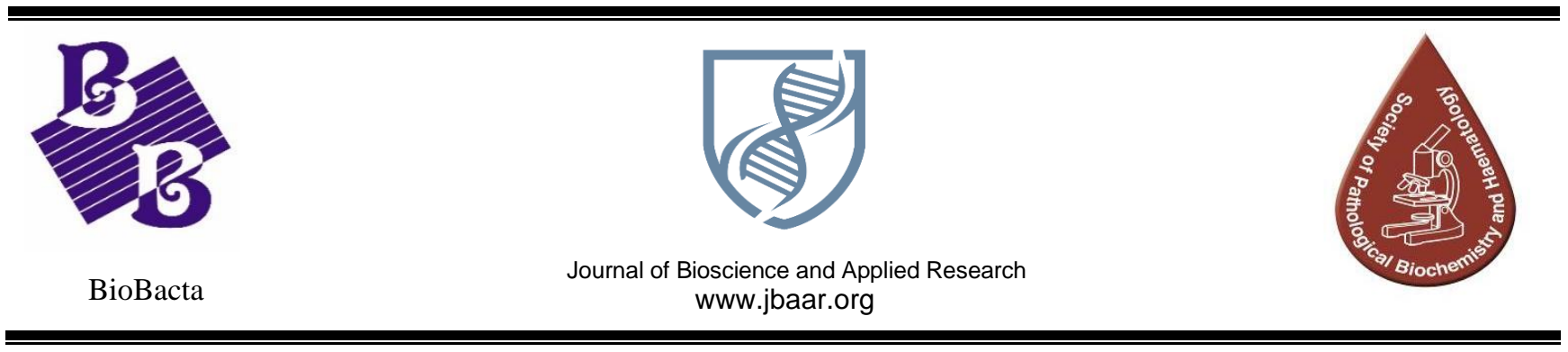

\title{
A comparative study of student's performance based upon TBL among two colleges in Khartoum, Sudan 2020
}

\author{
Safinaz I Khalil ${ }^{\mathbf{1}}$, Hiba Elzaki ${ }^{2}$, and Mohammed EA Elameen ${ }^{2}$ \\ Department of Pharmacology, Alfajr College of sciences and Technology ${ }^{1}$ \\ P.O.Box 150 Alfajr College of sciences and Technology, Sudan \\ Department of Community Medicine, Alfajr college of Sciences and Technology ${ }^{2}$ \\ POBox 234 Alfajr College of Sciences and Technology, Sudan \\ (drsafinaz17@gmail.com) \\ DOI: 10.21608/jbaar.2021.176408
}

\begin{abstract}
Introduction: Team-Based Learning establishes as a potential ramification educational strategy that ensures student's high performance. TBL guarantees active learning and critical thinking this impacts student's competency and improves their future achievements. This study aims to evaluate the effectiveness of TBL as a powerful educational strategy that fosters them for Problem based learning Curriculum. Methodology: Study Design: Descriptive prospective study. Study Area: College A and College B, Pharmacology course, Medicine, Khartoum, Sudan. Study duration from July 2019 -January 2020. Study Population Medical students in College A and College B in an introductory Pharmacology Course. Sample size: All students in the second year, college of Medicine attending the Pharmacology course will be included in college A and all students in the third year, college of Medicine attending the Pharmacology course included in college B. Methods: Purposeful convenient sampling method all second-year medical students who attended the introductory Pharmacology course in College A and all students in the third year who attended Pharmacology course in College B taught by the same Pharmacology Staff facilitator and received the same final exam questions. College A, students were taught in integrated course student-centered, team-based learning where they have a traditional lecture hall strategy. They are examined using best of four as a tool for assessment College B, students were taught in a traditional lecture hall method, teacher-centered. They are examined using the best of four as a tool for assessment. Final results were collected from each group in College A and college B and compared. Results: showed that the mean ranks for the subclasses of the final examination performance that there was a significant result 0.001 obtained in college A students and college B students grade $\mathrm{F}$ with a mean rank of 7.08 and 16.22 respectively. For students who had grade $\mathrm{C}$ also this is a significant result of 0.019 where students in college A mean rank was 25.89 and 38.46 respectively. For students who had grade A again, there is a significant result of 0.004 where a student in college A mean rank was 61 in comparison to students in college B where the student's mean rank was 43.88. In the other subclasses $\mathrm{C}+, \mathrm{B}$, and $\mathrm{B}+$ there were no significant differences $0.952,0.419$, and 0.837 respectively. Conclusion: TBL improved the outcome of the students at the exam in the extremes of marks those with category mark $\mathrm{C}$ and those in category mark A.
\end{abstract}

Keywords: TBL. Team-Based Learning, educational strategy, comparative study Received: April 5, 2021. Accepted: June 3, 2021. Published: June 8, 2021 


\section{Introduction}

Team-Based Learning establishes as a potential ramification educational strategy that ensures student's high performance. TBL guarantees active learning and critical thinking this impacts student's competency and improves their future achievements. This study aims to evaluate the effectiveness of TBL as a powerful educational strategy that fosters them for Problem based learning (2).

In late 1970, Larry Michalelsen structured Team-Based Learning in Business college. Larry employed the application of TBL learning in multiple small groups into large group scenery which differs from traditional learning. Medical educational experts perceived a new strategy of learning shifting from passive to active. Active pedagogy is preferred over passive. Providing students with the knowledge, skills, and attitude making them responsible for their learning not like the passive traditional one (3).

According to the scheduled timetable of the TBL, the session's academic facilitators attended TBL sessions consistently

The three TBL include three main processes $(3,4,6)$

1- TBL core part is planning by students

2-Developing the individual readiness assurance test (IRAT) consisting of multiple-choice questions with one single best answer where students implement formative assessment for their knowledge, this is followed by the similar test but on a team-based group, readiness assurance test (GRAT) studies found that the sores by (GRAT) is usually higher than (IRAT) and this tinted the prove for the TBL as an active learning method. Also, students satisfaction with the TBL experience were fruitful with acquiring critical thinking and teamwork experience (4)

3- Clinching of critical thinking by students on a team base, trailed by immediate feedback.

Since 2001 Team-Based Learning (TBL) was adopted as an educational strategy recommended for the later years of the medical education program. By reviewing

the literature, very few studies were found about TBL effectiveness and its relation to outcome (5). In 2010 a study approved the effectiveness of TBL on student's performance. Students' performance was higher in the lowest quartile in comparison to the higher one (5). Another study was done in 2015 provided evidence that students positively perceived the TBL learning strategy more than the traditional lecture method which promotes their proactive learning and they score high in their final assessment test (8).

Team-based learning was granted to improve the Pharmacology teaching to undergraduate students where they enjoy peer-peer interaction and develop skills to learn independently. (9) In South Africa, they found that TBL pedagogy motivates the students for teamwork which mimics the virtual reality platform of the health professions team. (10) Professional development is associated with TBL which is a spectacular expansion for future practitioners (11).

Many studies have been done in Kilimanjaro on TBL introduction and comparison of TBL to the traditional teaching pedagogy. Students' performance was high in the final exam and they show a high level of satisfaction. (12) Geographic trends in Team-Based Learning; Asia nowadays is a key driver in TBL collaborative research although North America previously considered the top. $(13,14)$

By reviewing the literature Publications in the US were 29 articles $(26,37.68 \%)$ which is the peaked number among the other world countries. Singapore and Lebanon each published about 5 (7.25\%) research papers. $(15,16)$

In Sudan, a study was done 2014-2015 showed that more than $60 \%$ of the students preferred Team-based learning to lecture. They thought that they were able to collaborate in a team and share their knowledge effectively. Final performance results were found to be very promising and TBL was an efficient instructional method of learning (17).

\section{Methods}




\section{Study Design}

Descriptive prospective study

\section{Study Area}

College A and College B, Pharmacology course, Medicine, Khartoum, Sudan

\section{Study duration}

From July 2019 -January 2020

\section{Study Population}

Medical students in College A and College B in an introductory Pharmacology Course

\section{Sample size}

All students in the second year, college of Medicine attending the Pharmacology course will be included in college A and all students in the third year, college of Medicine attending the Pharmacology course included in college B.

\section{Sampling methods}

Purposeful convenient sampling method all secondyear medical students who attended the introductory Pharmacology course in College A and all students in the third year who attended Pharmacology course in College B taught by the same Pharmacology Staff facilitator and received the same final exam questions.

College A, students were taught in integrated course student-centered, team-based learning where they have a traditional lecture hall strategy

They are examined using best of four as a tool for assessment

College B, students were taught in a traditional lecture hall method, teacher-centered. They are examined using best of four as a tool for assessment

Final results were collected from each group in College A and college B and compared

\section{Inclusion Criteria}

Third medical school students, college of Medicine attended the introductory Pharmacology course by the same instructor from Pharmacology department receiving the same exam.

\section{Exclusion criteria}

Dropped students, and external students are not included

\section{Ethical Consideration}

Ethical consent will be taken from College A and College B

\section{Results}

\section{Data Analysis}

Using Excel sheet to sort the marks for TBL and Final exam

Using SPSS (Statistical Package Specific Data) version 26

Table (1) Descriptive for student marks

\begin{tabular}{|c|c|c|c|c|c|}
\hline & $\mathrm{N}$ & $\begin{array}{c}\text { Minim } \\
\text { um }\end{array}$ & $\begin{array}{c}\text { Maxim } \\
\text { um }\end{array}$ & $\begin{array}{c}\text { Mea } \\
\mathrm{n}\end{array}$ & $\begin{array}{c}\text { Std. } \\
\text { Deviation }\end{array}$ \\
\hline A & $\begin{array}{c}11 \\
3\end{array}$ & 21 & 99 & $\begin{array}{c}70.5 \\
3\end{array}$ & 17.673 \\
\hline B & 31 & 41 & 96 & 70.0 & 10.942 \\
& 2 & & & 7 & \\
\hline
\end{tabular}

Table (1) showed that college A students $n=113$ and college $B$ students $n=312$ minimum results scored by college A was 21 while minimum results scored by college B was 41 .

The maximum results for college A were 99 while those for college B were 96.

The standard deviation for college A was 17.673 and for college, B was 10.942, alternatively.

The mean for college A was 70.53 and for college, B was 70.07 . 
Table (2) Sum of Ranks

\begin{tabular}{|l|l|c|c|c|}
\hline & College & $\mathrm{N}$ & Mean Rank & Sig. \\
\hline total & A & 113 & 223.01 & 0.312 \\
\hline & B & 312 & 209.38 & \\
\hline
\end{tabular}

Table (2) showed that college A students no= 113 and the mean rank was 223.01 while in college B students no $=312$ and the mean rank was 209.38 there was no significant difference between the two colleges regarding the rank mean.

Table (3) Mean ranks for the subclasses of the two colleges A and B final examination performance

\begin{tabular}{|l|l|c|c|c|}
\hline & College & $\mathrm{N}$ & Mean Rank & Sig. \\
\hline F & A & 12 & 7.08 & 0.001 \\
\hline & B & 9 & 16.22 & \\
\hline & & & & \\
\hline C & A & 19 & 25.89 & 0.019 \\
\hline & B & 50 & 38.46 & \\
\hline & & & & \\
\hline C+ & A & 18 & 45.67 & 0.952 \\
\hline & B & 73 & 46.08 & \\
\hline & & & & \\
\hline B & A & 9 & 29.61 & 0.419 \\
\hline & B & 59 & 35.25 & \\
\hline & & & & \\
\hline B+ & A & 13 & 36.88 & 0.837 \\
\hline & B & 62 & 38.23 & \\
\hline & & & & \\
\hline A & A & 42 & 61 & 0.004 \\
\hline & B & 59 & 43.88 & \\
\hline & & & & \\
\hline & & & \\
\hline & & & \\
\hline
\end{tabular}

Table (3) showed that the mean ranks for the subclasses of the final examination performance that there was a significant result 0.001 obtained in college A students and college $B$ students grade $F$ with a mean rank of 7.08 and 16.22 respectively.

For students who had grade $\mathrm{C}$ also this is a significant result of 0.019 where students in college A mean rank was 25.89 and 38.46 respectively.

For students who had grade A again, there is a significant result of 0.004 where a student in college A mean rank was 61 in comparison to students in college B where the student's mean rank was 43.88 .

In the other subclasses $\mathrm{C}+, \mathrm{B}$, and $\mathrm{B}+$ there were no significant differences $0.952,0.419$, and 0.837 respectively.

\section{Discussion}

Geographical trends of TBL, the Baylor College of Medicine (US) since 2000 was the first to implement Team-Based Learning among their students in health profession education and most of the publications in the era were from this college (13). There is an increasing number of research activities in Asia to prove the effectiveness of TBL as a strategy of active learning; hence the local traditional culture of single-gender team-based learning was studied by King AlFaisal University, College of Medicine, Saudi Arabia. (15)

As shown in table (1) the description of the data; college A students $n=113$ and college $B$ students $n=$ 312 minimum result scored by college A was 21 while the minimum result scored by college $\mathrm{B}$ was 41 . The maximum results for college A were 99 while those for college B were 96 . The standard deviation for college A was 17.673 and for college, B was 10.942. The mean for college A was 70.53 and for college, B was 70.07

Examination Performance Final Results were performed to compare the introductory Pharmacology Course between college A and College B where College A has TBL learning strategy and College B used the traditional lecture hall strategy with no TBL. The course enrolled 113students in college A and 312 
students in college B. One facilitator instructed the course and they received the same final exam questions. TBL exam was constructed for students in college A with the IRAT and IGRAT grading.

Table (2) showed that college A students no= 113 and the mean rank was 223.01 while in college B students no $=312$ and the mean rank was 209.8 there was no significant difference between the two colleges regarding the rank mean.

In-depth analysis of the distribution categories then surveyed. The outcome of this study showed significant differences $(0.001,0.019$, and 0.004) in those who failed the exam and those who attained rank $\mathrm{A}$ and $\mathrm{C}$, respectively. But did not show significance among those who attained $\mathrm{C}+, \mathrm{B}, \mathrm{B}+$. In other words, TBL improved those in the extremes (category $\mathrm{A}$ and category C). For Grade F in college A, they have low entry results also low attendance rate, and above all, they were in the second medical school. That could explain the significant result that appeared with this group.

In 2015 a study showed that the students with high marks met the advantage of TBL for good performance. (17) Also another study in 2019 showed that after implementation of TBL, the high score students achieved more credits than low score students (19). In one of the studies done in 2010 students within the lowest quartile students showed uppermost benefit from TBL than the highest quartile (5).

Table (3) showed that the mean ranks for the subclasses of the final examination performance that there was a significant result 0.001 obtained in college A students and college $B$ students grade $F$ with a mean rank of 7.08 and 16.22 respectively.

For students who had grade $\mathrm{C}$ also this is a significant result of 0.019 where students in college A mean rank was 25.89 and 38.46 respectively.

For students who had grade A again, there is a significant result of 0.004 where a student in college A mean rank was 61 in comparison to students in college B where the student's mean rank was 43.88 .

In the other subclasses $\mathrm{C}+, \mathrm{B}$, and $\mathrm{B}+$ there were no significant differences $0.952,0.419$, and 0.837 respectively.

This descriptive study was done to compare between medical students of College A and college B regarding the introductory pharmacology course where College A has TBL in addition to the final exam while College B has only no TBL but the final exam.

TBL improved the outcome of the students at the exam in the extremes of marks those with category mark $\mathrm{C}$ and those in category mark $\mathrm{A}$.

\section{Conclusion}

The results showed that there is no significant difference between the two groups and this could be due to the difference in the student's levels between the two colleges as one may be astute than the other. Another thing is those apprentices in college A are in semester 3 and those in college B are in Semester 5.Also the curriculum in college $\mathrm{A}$ is integrated whereas that of college B is traditional. Exams were different among the two colleges where the one in College A was MCQs plus Structured Short Answered Questions while for those in College B it was MCQs only. Although the candidates in college A and college $B$ received the same introductory pharmacology course taught by the same facilitator.

\section{References}

1-Jabbar, Hussein A et al. "Effectiveness of the teambased learning (TBL) strategy on medical students' performance." Journal of Taibah University Medical Sciences vol. 13,1 70-76. 16 Dec. 2017, doi:10.1016/j.jtumed.2017.09.003

2- RefSuno M, Yoshida T, Koyama T, Zamami Y, Miyoshi T, Mizushima T, Tanimoto M. Yakugaku Zasshi. et al 2013 [Effectiveness of Team-Based Learning (TBL) as a new teaching approach for pharmaceutical care education],133(10):1127-34. 
3- Richard F. Yuretich1,a and Lisa C. Kanner et al. 2015 .Examining the Effectiveness of Team-Based Learning (TBL) in Different Classroom Settings. JOURNAL OF GEOSCIENCE EDUCATION. 63, 147-156.

4- F. Yuretich, a and Lisa C. Kanner. et al (2015) Examining the Effectiveness of Team-Based Learning (TBL) in Different Classroom Settings Richard. JOURNAL OF GEOSCIENCE EDUCATION. 63, $147-156$

5-Koles PG1, Stolfi A, Borges NJ, Nelson S, Parmelee DX. Et al 2010 Nov. The impact of team-based learning on medical students' academic performance.Acad Med.; 85(11):1739-45.

6-RefSuno M, Yoshida T, Koyama T, Zamami Y, Miyoshi T, Mizushima T, Tanimoto M. et al 2013.Effectiveness of Team-Based Learning (TBL) as a new teaching approach for pharmaceutical care education. Yakugaku Zasshi.; 133(10):1127-34.

7-Jabbar, Hussein A. et al 16 Dec 2017. Effectiveness of the team-based learning (TBL) strategy on medical students' performance. Journal of Taibah University Medical Sciences vol. 13,1 70-76.

8-Richard F. Yuretich ,a and Lisa C. Kanner . et al 2015. The impact of team-based learning on medical students' academic performance. JOURNAL OF GEOSCIENCE EDUCATION; 63, 147-156.

9- Nayana K. Hashilkar, Mark H. Gelula, Netravathi B. Angadi. Et al 2016.Effectiveness and student perspective of a pilot effort in team based learning in pharmacology for medical undergraduate.IJBCP $\operatorname{Vol}(5)$ No (4).

10- Mariet J. Eksteen,a,b Gerda M. Reitsma,b Sonet B. Swart,a Erika Fourie, et al 2018. Team-Based Learning Experiences of Fourth-Year Pharmacy Students in a South African University American Journal of Pharmaceutical Education; 82 (1).
11-M.J. Eksteen. Et al 2019. South African Journal of Higher Education - Does team-based learning develop essential generic skills in pharmacy students? South African Journal of Higher Education, Volume 33 Number 1, p. $59-73$.

12-Nyindo, M., Kitau, J., Lisasi, E., Kapanda, G., Matowo, J., Francis, P., \& Bartlett, J.et al 2014 . Introduction of team-based learning (TBL) at Kilimanjaro Christian Medical University College: experience with the ectoparasites module. Medical teacher, 36(4), 308-313.

13- Jimmy Ming, Hong Preman, Rajalingam et al 2019 Geographic. Trends in Team-Based Learning (TBL) research and implementation in medical schools. Health professions Education

14- Richard F. Yuretich1,a and Lisa C. Kanner.et al 2015. Examining the Effectiveness of Team-Based Learning (TBL) in Different Classroom Settings JOURNAL OF GEOSCIENCE EDUCATION 63, $147-156$

15- Joyce Addo-Atuah et al 2011. Performance and Perceptions of Pharmacy Students using Team-based Learning (TBL) within a Global Health Course. INNOVATIONS in Pharmacy.Vol 2 No 22011

16- KARIMELDIN M. A. SALIH.et al 2018. Quality of Medical Students Performance through Team-Based Learning in Comparison to Performance in Traditional Lecture, P J M H S Vol. 12, NO. 4.

17- Karoum, Abuelgasim Osman et al 20152015.Perception of Team-based Learning in Pathology Course among Fourth Year Medical Students Faculty of Medicine, University of Kassala, Sudan

18- Jian Wei Li . et al 2019.The impact of team based learning on students with different self-regulated learning abilities. Journal of Computer Assisted Learning. Vol 35 (6 